\title{
Chinglish in the Oral Work of College Students
}

\author{
Jing Xiao \\ Foreign Languages Department, Zhuhai CollegeJilin University, Zhuhai, China
}

Keywords: Chinglish; oralwork; college students; English learning and teaching

Abstract: Chinglish is one of the major problems in the oral English of Chinese College students. This problem often hinders oral expression and intercultural communication. This paper aims to measure students' Chinglish at four different levels: pragmatic, lexical, phonetic and syntactic level and focuses on answering two questions: which type of Chinglish occurs most frequently? Is there any correlation between the students’ oral English learning strategies and Chinglish?

\section{Introduction}

As international business develops, the need for proficient English speakers in China has ever been increasing, which drives many colleges and universities to offer oral classes and many students to learn and practice oral English. Although the enthusiasm for oral English has increased, the oral proficiency of college students is far from satisfactory, much Chinglish existing in their oral work. Chinglish can be destructive and frequent occurance may lead to pragmatic or communicative failures.

\section{Definition of Chinglish}

In foreign language learning process, learners' errors have long been the focus of attention of linguists and language teachers. And in China, learners' unidiomatic English in their speech and written work, which is called Chinglish has drawn much attention of Chinese linguists and even some foreign teachers who are working in China. Ge Chuanghui was the first scholar who proposed the term Chinglish and China English in his essay "On Chinese to English Translation". According to Deng Yanchang, Chinglish is a speech or writing in English that shows the interference or influence of Chinese, some sentences may be little or more than word to word translation of Chinese expressions. Chinglish may be grammatically correct, but the choice of words and phrases and the manner of expression do not conform to standard usage. Although understanding may be a problem, Chinglish is unacceptable. [1]. Many other scholars thought that the existence of Chinglish is objective, and pointed out that it is an unavoidable language phenomenon. According to $\mathrm{Li}$ Wenzhong, Chinglish is misshapen English which is produced by Chinese learners who draw upon Chinese rules and structures mechanically as a result of mother tongue interference. [2] Joan Pinkham, in her book The Translator's Guide to Chinglish, points out "Chinglish... is that misshapen, hybrid language that is neither English nor Chinese but that might be described as "English with Chinese characteristics." [3] In short, Chinglish is the erroneous or inappropriate product in English resulting from the use of Chinese patterns or rules or influenced by Chinese patterns of thought. Even though some of them have been adopted by native speaker of English in their daily communication like "Long time no see.”; "You go tell him!”. Chinglish is generally considered unacceptable.

\section{Research Design}

Subjects: 120 college freshmen were selected from four different majors. The students had attended oral English classes for almost one year, as the study was carried out at the end of their second semester.

\section{Instruments:}

Test Paper.The test paper is self-designed and consists of four parts, aiming to measure students' Chinglish at four levels: pragmatic, lexical, phonetic and syntactic level. Design of the test paper is in accordance with the features of Chinglish on the four levels. Forty multiple-choice questions are 
contained and for each question only one option is correct and the others are distractors, most of which are Chinglish.

Questionnaire.An oral English learning strategy questionnaire was conducted to gain a deeper understanding of what seemed to have made the main difference between high-score and low-score students in the test. The questionnaire consists of two parts. Part A includes five statements, concerning their beliefs about the involvement of mother tongue in oral English learning. Part B is composed of ten statements concerning their individual experiences in oral English learning strategies. Statements in the questionnaire adopted from Wen’s “learner's strategies”[4].

\section{Results and Discussion}

High Frequency of Chinglish on Lexical Level.The actual number of Chinglish errors collected from the sample test papers is presented in table 1. It shows that of all these errors, Chinglish on lexical level are the most distinctive, which count 533, about 34.90\%; next comes Chinglish at pragmatic level, accounting for $28.60 \%$ of the total. Chinglish errors on the level of syntax and pronunciation are $18.80 \%$ and $17.7 \%$ respectively.

\section{Table 1. Total Number and Proportion of Each Kind of Errors}

\begin{tabular}{|l|c|c|c|c|l|}
\hline $\begin{array}{l}\text { Types of Chinglish } \\
\text { Distribu- } \\
\text { tion of Errors }\end{array}$ & Pragmatics & Pronunciation & Lexicon & Syntax & Total \\
\hline Number of error & 437 & 270 & 533 & 287 & 1527 \\
\hline Proportion & $28.60 \%$ & $17.70 \%$ & $34.90 \%$ & $18.80 \%$ & $100 \%$ \\
\hline
\end{tabular}

Reasons for High Frequency of Chinglish on Lexical Level.High frequency of Chinglish on lexical level indicates that the biggest difficulty for students to reduce Chinglish is lexis. This may be because:

Firstly, lexical difference ---- the fundamental difference between languages .Language consists of words which are basically the smallest meaningful units. Due to the different cultures, people speaking different languages have their own ways ofexpressing ideas. Therefore, the basic difference between languages lies in the different use of words, for example different in denotations or connotations.

Secondly, negative transfer from the first language. The term "language transfer" has two sides. It can be positive and negative. When both the native language and the target language have the same form, pattern or rule, positive transfer occurs and it facilitates learning----that is , the prior knowledge benefits the learning task or a previous item is correctly applied to present subject matter. Negative transfer hampers learning. It occurs when the first language interferes in the foreign language learning.

Thirdly, Chinglish on the Lexical level induced by teaching.In China's oral English classrooms, when explaining an unknown word or a phrase, teachers usually spend much time explaining the formation, synonyms, and syntactic usage of the new item, little attention is given to cultural difference and pragmatic rules of the word. This kind of teaching practice can only be helpful for the students to memorize the word rather than acquire it because knowing that a letter string forms a word, or even knowing its meaning, does not tell us much about whether one is able to actually use the word appropriately and efficiently in communication [5]

Different Learning StrategiesBetween High-score and Low-score Groups. In 99 valid sample test papers, the scores higher than 84 were labeled high-score ones, and the scores lower than 66 were labeled low-score ones. 20 students from the two groups were randomly chosen to answer a questionnaire. A T-test on the questionnaire is performed to examine the differences in learning strategies. 
Table 2.significant difference in the use of oral English learning strategies

\begin{tabular}{|c|l|l|l|l|l|l|l|c|}
\hline $\begin{array}{l}\text { Strate- } \\
\text { gies }\end{array}$ & $\begin{array}{l}\text { Means of } \\
\text { High-sco } \\
\text { re group }\end{array}$ & $\begin{array}{l}\text { Means of } \\
\text { Low-score } \\
\text { group }\end{array}$ & $\begin{array}{l}\text { Mean } \\
\text { Difference }\end{array}$ & $t$ & df & $\begin{array}{l}\text { Sig. } \\
(2-\text {-taile } \\
\text { d) }\end{array}$ & \multicolumn{2}{|l|}{$\begin{array}{l}\text { 95\%Confidence } \\
\text { Interval } \\
\text { of the Difference }\end{array}$} \\
\hline & & & & & & & Lower & Upper \\
\hline 7 & 3.9500 & 3.1500 & 0.8000 & 2.421 & 38 & 0.020 & -0.33533 & 1.03533 \\
\hline 8 & 3.9000 & 3.2000 & 0.7000 & 2.534 & 38 & 0.016 & -0.82422 & 0.52422 \\
\hline 12 & 4.0000 & 3.4500 & 0.5500 & 2.065 & 38 & 0.046 & 0.01088 & 1.08912 \\
\hline 13 & 3.4500 & 2.7000 & 0.7500 & 2.915 & 38 & 0.006 & 0.22920 & 1.27080 \\
\hline 15 & 3.9000 & 3.2000 & 0.7000 & 2.131 & 38 & 0.040 & 0.03504 & 1.36496 \\
\hline
\end{tabular}

Table 2 shows the greatest difference between these two groups on the statement 7,12, which shows that high-score group attach more importance to English culture and idioms on their process of learning oral English, and they make more conscious efforts to memorize English idioms and customs. The significant difference on the statement 13, 15 shows high-scores rely less on mother tongue to speak English. The difference on the statement 8 probably tells us the reason why the students in high-score group have fewer Chinglish in the aspect of pronunciation in the test. As the students in this group often listen and imitate the pronunciation and intonation of authentic English recordings. Wen said in "On English learning strategies" [4] that to listen and imitate the pronunciation and intonation of authentic English tapes is a good and effective way to improve one's pronunciation.

\section{Implications for Oral English Teaching in China}

The study is valuable in two respects. In the first place, the investigation shed light on the research into the nature of Chinglish. In the second place, the implications drawn from the findings of the study will help to make improvements of oral English teaching and learning. The study has the following implications:

Firstly, English teachers should develop an objective, tolerable and positive attitude towards Chinglish. "Objective" means teachers should recognize the fact that Chinglish is an unavoidable stage in English learning of college students. "Tolerable” means that teachers should give advice or correct the students' Chinglish expressions on the premises that the correction will not cause negative effects on the students' interests towards English. "Positive" indicates teachers should have the confidence that it can be reduced through his/her appropriate teaching and students' effort.

Secondly, oral English teachers should attach great importance to lexical teaching and help the students to get rid of the false assumption on the semantic and syntactic equivalence of English and Chinese. And it is also important for the teacher to explain the pragmatic rules and cultural difference of a new word or to put it in a given context for the students to see the right situation the word is in.

Thirdly, teachers should increase students' cultural awareness and help students to develop English thought pattern. As Li said that with cultural exchanges intensified between China and the West, this unaccepted form of English will be diminished [2].

Last, successful oral English learners' strategies should be known by students. From the study, we know the degree of Chinglish has a close connection with the strategies adopted by students. A study by O'Malley and Chamot also suggests that effective foreign language learners are aware of the learning strategies they use and why they use them [6] .

\section{Acknowledgment}

This research was financially supported by “China Foreign Languages Educational Fund”.No. ZGWYJYJJ2014A44 


\section{References}

[1] Deng Yanchang Language and Culture. Beijing: Foreign Language Teaching and Research Press.(1989).

[2] Li Wenzhong. China English and Chinglish.Foreign Language Teaching and Research Vol 4 (1993),p. 18-24.

[3] H.S, R.Jenkin in Undersanding text in a second language: A psychological approach to an SLA problem. Second Language Research Vol 9.(1993).p. 118-39

[4] Wen Qiufang. On English Learning strategies Shanghai: Shanghai Foreign

Language Education Press. (1996).

[5] N \& A. Ellis, Psycholinguistic determinants of foreign language vocabulary learning Language learning. Beaton.Vol. 43 (1993), p. 559-617

[6] J. M. O’Malley,\& A. U. Chamot. Learning Strategies in Second Language Acquisition Cambridge: Cambridge University Press.(1990). 